\title{
Flow Injection Analysis of (-)-Epigallocatechin Gallate in Green Tea Infusions with an Immobilized Tannase Reactor
}

\author{
Hideki Horie, ${ }^{1}$ Toshihiro Mukal, ${ }^{1}$ Katsunori KoHata ${ }^{1}$ and Tetsuhisa Goto ${ }^{2}$ \\ ${ }^{1}$ National Research Institute of Vegetables, Ornamental Plants and Tea, 2769, Kanaya, Shizuoka 428, Japan \\ ${ }^{2}$ National Food Research Institute, 2-1-2, Kannondai, Tsukuba, Ibaraki 305, Japan
}

Received June 4, 1996

\begin{abstract}
A flow injection method to determine the concentrations of (-)-epigallocatechin gallate (EGCG) in tea infusions was developed. A bioreactor, packed with immobilized tannase, was connected to a pH-ISFET (Ion Sensitive Field Effect Transistor) electrode. The pH decrease, due to the gallic acid produced from EGCG by the enzyme reaction, was monitored by the electrode. The response of this system was linear between $50 \mathrm{mg} / l$ and 1,000 $\mathrm{mg} / l$ of EGCG. The sample could be injected every $3 \mathrm{~min}$. The concentrations of EGCG in green tea infusions obtained by this FIA method showed a fairly high correlation with those by HPLC.
\end{abstract}

Keywords: biosensor, FIA, enzyme reactor, ISFET, tea, EGCG

Most of the teas produced in Japan are green tea, and it is said that the harmonization of Umami (monosodium glutamate-like, brothy taste) and astringency is important for the quality of Japanese green tea (Nakagawa, 1975). Umami of green tea arises from free amino acids, which can be measured by high performance liquid chromatography (HPLC) (Ikegaya et al., 1990; Goto et al., 1993) or colorimetric methods (Ikegaya et al., 1990). For the purpose of rapid amino acid analysis, we have already developed a flow injection analysis (FIA) system using an enzyme-immobilized membrane and a Clark-type oxygen electrode (Horie et al., 1993a, b). On the other hand, the astringency of tea is due to catechins. Tea leaves contain four major catechins, (-)-epicatechin (EC), (-)-epigallocatechin (EGC), (-)-epicatechin gallate (ECG) and (-)-epigallocatechin gallate (EGCG), among which both EGCG and ECG show the strongest astringency (Nakagawa, 1972). Among the four catechins, the content of EGCG is the highest both in tea leaves and green tea infusions (Nakagawa \& Nakajima, 1972). Recently EGCG has also received attention due to its prophylactic functions, such as cancer prevention, suppression of cholesterol levels in blood and inhibitory action on a rise in blood pressure (Hara, 1994; Yamamoto, 1996). Tea catechins can be measured colorimetrically (Ikegaya et al. 1990) or using HPLC (Komatsu et al., 1993; Goto et al., 1996). We have already developed a biosensor using a slice of plant root combined with an oxygen electrode (Horie et al., 1994). A colorimetric or biosensor method is rather easy and rapid but shows poor selectivity for eacis catechin, whereas HPLC methods show high selectivity but need skill and longer analysis time. An analytical method which is rapid, easy and selective for EGCG is required to estimate the taste and prophylactic functions of green tea.

FIA using enzyme reactors has also been applied to the field of food analysis as a highly selective and rapid method (Schwedt \& Stein, 1994; Ukeda, 1995; Schügerl et al., 1996).
We have developed a new FIA method to measure EGCG quickly and rather selectively. The principle behind this analysis is to measure the $\mathrm{pH}$ shift depending on the enzyme reaction. We used tannase (EC 3.1.1.20) and a pH-ISFET (Ion Sensitive Field Effect Transistor) electrode for the reaction and $\mathrm{pH}$ measurements, respectively. The reaction of the enzyme, when EGCG is used as a substrate, is as follows:

$$
\begin{aligned}
& (-) \text {-epigallocatechin gallate }+\mathrm{H}_{2} \mathrm{O} \longrightarrow \\
& \qquad(-) \text {-epigallocatechin }+ \text { gallic acid }
\end{aligned}
$$

The gallic acid produced in this reaction changes the $\mathrm{pH}$ of the reaction mixture. The $\mathrm{pH}$ decrease in the tannase immobilized reactor was monitored by a downstream ISFET electrode.

Recently, Chen \& Matsumoto (1995) has also reported a method for the determination of EGCG and other catechin gallates in tea infusions by using tannase. They measured gallic acid, released by the enzyme reaction, by a chromogenic reaction with rhodamine. In their method, samples must be preincubated with tannase for $1 \mathrm{~h}$, whereas in our method samples can be directly injected into the FIA system. Our method reported here is much easier and quicker than theirs.

\section{Materials and Methods}

Apparatus and reagents The $\mathrm{pH}$-ISFET electrodes and ISFET $\mathrm{mV} / \mathrm{pH}$ meter were purchased from Sindengen Electric (Tokyo). A reference electrode ( $\mathrm{Ag} / \mathrm{AgCl}, \mathrm{RE}-1 \mathrm{~B})$ and flow-through cells for an ISFET electrode and reference electrode were purchased from BAS (Tokyo). Tannase (Aspergillus oryzae, 49 units/mg) and aminopropylated controlled pore glass (CPG, mean pore diameter $521 \AA$, particle size 120/200) were obtained from Wako Pure Chemicals (Osaka) and CPG, Inc. (NJ), respectively. Tea catechins including EGCG were obtained from Kurita Kogyo (Tokyo). These chemicals were used as received.

Preparation of enzyme reactors Tannase was im- 
mobilized on CPG according to the method of Murachi \& Tabata (1988). A volume of $1 \mathrm{ml}$ of phosphate buffer ( $\mathrm{pH} 7.0$, $50 \mathrm{~mm}$ ) containing $20 \mathrm{mg}$ of tannase was added to glass beads, pretreated with glutaraldehyde. The mixture was stored overnight (about $16 \mathrm{~h}$ ) at $4^{\circ} \mathrm{C}$. After washing with phosphate buffer containing $1 \mathrm{M}$ sodium chloride, the tannase-immobilized glass beads were stored in phosphate buffer at $4^{\circ} \mathrm{C}$. The glass beads were packed into a piece of silicone tube (i.d. $=1 \mathrm{~mm}$ ) to make an enzyme reactor. The length of the reactor tube was about $20 \mathrm{~mm}$.

Bovine serum albumin (BSA) was immobilized on glass beads and packed in a reactor by the same methods as those for tannase.

Measurement of tannase activity The activity of immobilized tannase was measured as follows. The reaction mixture $(5 \mathrm{mg}$ of tannase-immobilized glass beads and 0.5 mM of EGCG or other substrates in $100 \mathrm{~mm}$ phthalate buffer) was incubated at $20^{\circ} \mathrm{C}$ for $40 \mathrm{~min}$. The gallic acid produced from the EGCG was analyzed by HPLC. In the case of measurement of the activity of free enzyme, the amount of enzyme added was $0.1 \mu \mathrm{g}$ and other analytical conditions were the same as in the case of immobilized enzyme. The conditions for HPLC are described below as the analytical method for tea catechins.

Construction of the FIA system The system constructed is shown in Fig. 1. Distilled water and phthalate buffer ( 10 $\mathrm{mM}, \mathrm{pH} 5.5$ ) containing $500 \mathrm{~mm}$ of sodium chloride were pumped by a multi-channel peristaltic pump (Multipuls 3, Gilson, WI) at a total flow rate of $0.7 \mathrm{ml} / \mathrm{min}$. Sodium chloride was added to decrease the noise of the baseline. The pulsating flows were reduced by pulse-dampeners. The sample solution was injected from an injection valve (Type 50 , Rheodyne, CA) with a $100 \mu 1$ sampling loop. The sample injected was mixed with the buffer solution, and subsequently the mixture was divided into two paths. The flow rate of each path was adjusted at $0.35 \mathrm{ml} / \mathrm{min}$ with a back pressure coil. One path was connected to the tannase-immobilized reactor, while the other was connected to the BSA-immobilized reactor. The $\mathrm{pH}$ shift caused by both the tannase reaction and the $\mathrm{pH}$ of the sample itself was monitored by the ISFET electrode connected to the tannase reactor. On the other hand, the $\mathrm{pH}$ shift caused by the $\mathrm{pH}$ of the sample itself was also monitored by another ISFET electrode connected to the BSA reactor. The $\mathrm{pH}$-difference between these two electrodes, which equals the $\mathrm{pH}$ shift caused by tannase reaction alone,

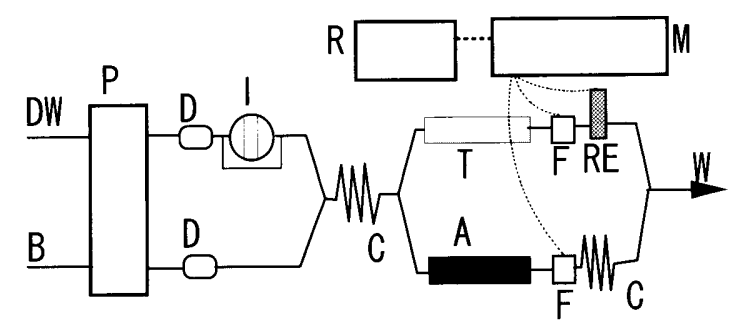

Fig. 1. Schematic diagram of the flow injection analysis system for EGCG. DW, distilled water; B, buffer; $\mathrm{P}$, peristaltic pump; D, pulse-dampener; I, injection valve; $\mathrm{C}$, coil; $\mathrm{T}$, tannase-immobilized reactor; $\mathrm{A}$, BSA-immobilized reactor; $\mathrm{F}$, pH-ISFET electrode; $\mathrm{RE}$, reference electrode; $\mathrm{W}$, waste; $\mathrm{M}$, ISFET $\mathrm{pH} / \mathrm{mV}$ meter; $\mathrm{R}$, recorder. was recorded as a potential difference.

The tea infusion was filtered with filter paper (No. 2, Advantec Tokyo) before being injected into this system. The measurements were carried out at room temperature (about $\left.20^{\circ} \mathrm{C}\right)$.

Measurement of tea catechins by HPLC Catechins in tea infusions were determined by a HPLC system (LC-6A, Shimadzu, Kyoto) fitted with a UV detector (set at $280 \mathrm{~nm}$ ) and an ODS column (Capcell Pak UG-120; particle size, 5 $\mu \mathrm{m} ; 250 \mathrm{~mm} \times 4.6 \mathrm{~mm}$ i.d.; Shiseido, Tokyo) at an oven temperature of $40^{\circ} \mathrm{C}$. The mobile phase was water $(81.5 \%)$, methanol (18\%) and phosphoric acid $(0.5 \%)$. The tea infusions were diluted 10 times with distilled water and filtered by a membrane filter $(0.45 \mu \mathrm{m}$ pore size $)$. A volume of $10 \mu \mathrm{l}$ of the solution was injected.

\section{Results and Discussion}

Properties of free and immobilized tannase The specificity of free and immobilized tannase was compared (Table 1). The substrates tested were the four major catechins in tea leaves; EGCG, ECG, EGC, EC, and two minor tea catechins; (-)-gallocatechin gallate (GCG) and (-)-catechin gallate (CG). The structure of these catechins is shown in Fig. 2. This enzyme did not produce gallate from EGC or EC. In the case of free enzyme, the gallate releasing activity was dependent on the structures of the ester-type catechins, whereas in the case of immobilized enzyme it seemed to be independent of the structures. It is considered that this FIA shows the same degrees of response to the same concentrations of these ester-type catechins. Because EGCG constitutes most of the tea catechins, most of this work was carried out using EGCG as a substrate.

Determination of analysis conditions The $\mathrm{pH}$ dependence of the activity of immobilized tannase was determined

Table 1. Comparison of gallate releasing activity from various catechins by free and immobilized tannase.

\begin{tabular}{lcc}
\hline & Free enzyme (\%) & Immobilized enzyme (\%) \\
\hline EGCG & $100^{a)}$ & $100^{b)}$ \\
ECG & 163 & 101 \\
EGC & 0 & 0 \\
EC & 0 & 0 \\
GCG & 67 & 99 \\
CG & 57 & 98 \\
\hline
\end{tabular}

Enzyme activities were measured at $\mathrm{pH} 5.5,20^{\circ} \mathrm{C}$.

a) $37 \mu \mathrm{mol} / \mathrm{mg}$ enzyme $/ \mathrm{min},{ }^{b)} 0.5 \mu \mathrm{mol} / \mathrm{g}$ glass beads $/ \mathrm{min}$

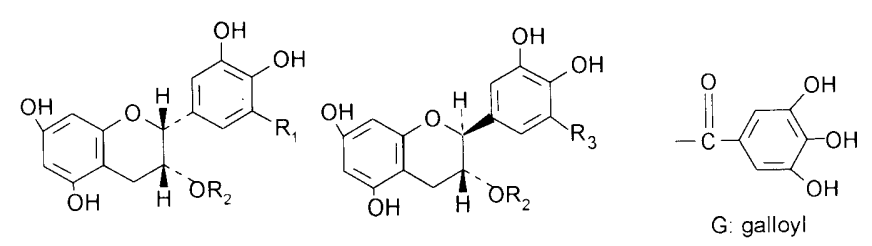

Fig. 2. Structures of tea catechins.

$\begin{array}{llccc} & & R_{1} & R_{2} & R_{3} \\ \text { (-)-epigallocatechin gallate } & \text { EGCG } & \text { OH } & \mathrm{G} & - \\ \text { (-)-epicatechin gallate } & \text { ECG } & H & G & - \\ \text { (-)-epigallocatechin } & \text { EGC } & \text { OH } & H & - \\ \text { (-)-epicatechin } & \text { EC } & H & H & - \\ \text { (-)-gallocatechin gallate } & \text { GCG } & - & \mathrm{G} & \mathrm{OH} \\ \text { (-)-catechin gallate } & \mathrm{CG} & - & \mathrm{G} & \mathrm{H}\end{array}$




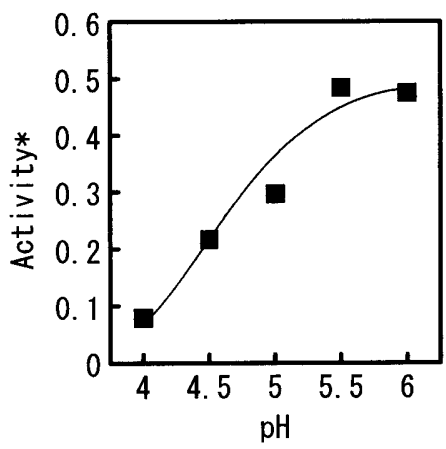

Fig. 3. The $\mathrm{pH}$ dependence of the gallate producing activity of the tannaseimmobilized glass beads. * $\mu \mathrm{mol}$ of gallate produced $/ \mathrm{g}$ of glass beads $/ \mathrm{min}$.

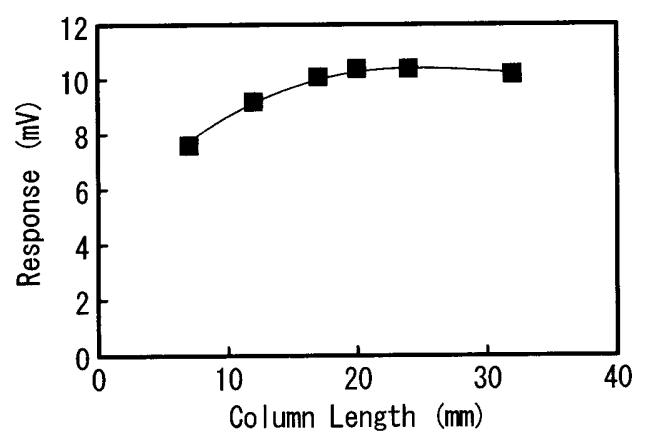

Fig. 4. Effect of the tannase reactor column length of tannase reactor on the response of the FIA system. Phthalate buffer ( $\mathrm{pH} 5.5,10 \mathrm{~mm}$ ) containing 500 $\mathrm{mm} \mathrm{NaCl}$ was used and $600 \mathrm{mg} / \mathrm{l}$ of EGCG was injected.

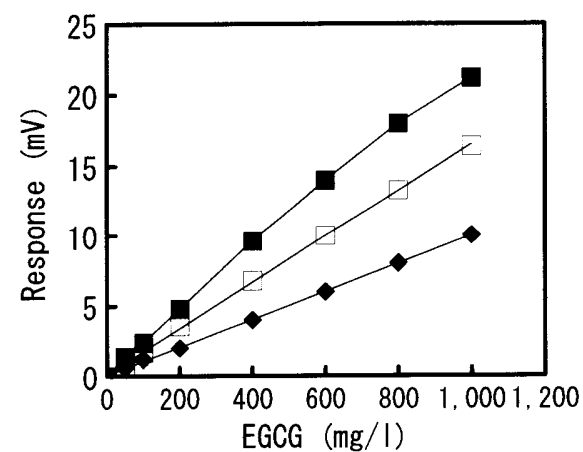

Fig. 5. Calibration graphs for EGCG under three different buffer concentrations. Phthalate buffer concentrations: $5 \mathrm{~mm}, \sqcap 10 \mathrm{~mm}, \diamond 20 \mathrm{~mm}$.

over the range of $\mathrm{pH} 4.0-6.0$ (Fig. 3). The highest activities were observed around pH 5.5-6.0. Because EGCG is unstable at high $\mathrm{pH}$, a $\mathrm{pH}$ of 5.5 was chosen for the analysis.

The length of the tannase column also had an effect on the system's response. The response to EGCG was compared among tannase columns of varying lengths (Fig. 4). The flow rate did not decrease with increasing length of the columns within the ranges tested. The reactor response showed a maximum at a column length of $20 \mathrm{~mm}$ or longer; therefore this length was chosen. Under these conditions, samples were continuously injected every $3 \mathrm{~min}$.

The response to EGCG did not decrease during 50 or more times of successive analysis, and the reactor column could be practically reused after 1 week storage in a refrigerator. However, $80 \%$ of the response was lost when the reactor was used during the daytime and stored at room temperature at
Table 2. Recovery test of EGCG from tea infusions.

\begin{tabular}{rcc}
\hline & Measured value $^{a)}(\mathrm{mg} / l)$ & Recovery (\%) \\
\hline Tea extract A & $544 \pm 5$ & - \\
$+125 \mathrm{mg} / l$ & $668 \pm 8$ & 99 \\
$+250 \mathrm{mg} / l$ & $786 \pm 8$ & 97 \\
Tea extract B & $360 \pm 8$ & - \\
$+125 \mathrm{mg} / l$ & $484 \pm 4$ & 99 \\
$+250 \mathrm{mg} / l$ & $602 \pm 5$ & 97 \\
\hline
\end{tabular}

a) Mean \pm S.D. $(n=3)$.

Tea extract A: low grade green tea (low grade Sen-cha), Tea extract B: high grade green tea (Gyokuro).

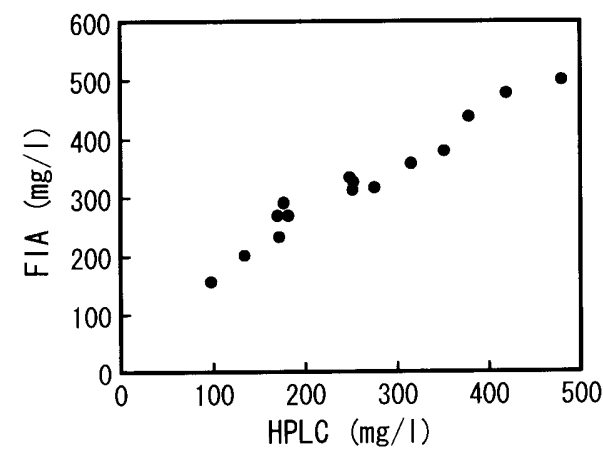

Fig. 6. Comparison of EGCG concentrations in tea infusions as determined by HPLC and FIA methods.

night over the course of a week. On the other hand, the immobilized enzyme itself stored in phosphate buffer at $4^{\circ} \mathrm{C}$ did not show any decrease in activity for more than 3 months. Because less than $5 \mathrm{~min}$ is needed to pack the immobilized tannase to make a reactor, we recommend that a new reactor be prepared immediately before use.

The calibration curves for EGCG are shown in Fig. 5. A high concentration of the buffer seemed to suppress the system's response. When $5 \mathrm{~mm}$ phthalate buffer was used, the responses were the highest; however, the calibration curve was linear only below $600 \mathrm{mg} / \mathrm{l}$ of EGCG. Because the maximum concentration of EGCG in common tea infusion is supposed to be less than $1,000 \mathrm{mg} / \mathrm{l}$ (Nakagawa \& Nakajima, 1972; Komatsu et al, 1993), we chose a buffer concentration of 10 $\mathrm{mM}$. At this concentration, the calibration curve is linear $(r=$ 0.999 ) between $50 \mathrm{mg} / l$ and $1,000 \mathrm{mg} / l$.

The performance of the FIA system The results of the recovery of EGCG added to the tea infusions are shown in Table 2 . The recovery rates were almost $100 \%$, when known levels of EGCG were added to the infusions of both high and low grade teas.

The selectivity of this FIA method was also tested. Among the four major catechins in tea, EC or EGC showed no response. Caffeine or theanine, which are also the major components of tea, also showed no response. On the other hand, ECG showed the same level of response as EGCG at the same molar concentrations. It is reported that the concentration of EGCG is usually several times higher than that of ECG (Nakagawa \& Nakajima, 1972; Takayanagi et al., 1985). Moreover, the astringency of ECG is not much stronger than that of EGCG (Nakagawa, 1972). The existence of ECG could be ignored in a rough and rapid analysis for the estimation of the taste or the quality of green tea.

The results obtained by our method were compared with 
those using HPLC (Fig. 6). The samples measured were the filtrates of tea infusions that were infused from four kinds of green tea under various conditions. The correlation of the results between these two methods was fairly good ( $r=0.98)$, although the values themselves did not agree precisely. There are several reasons for this discrepancy. One reason is the existence of ECG and other minor ester-type catechins, such as GCG or CG, in tea infusions. In our FIA method, the existence of these ester-type catechins would lead to higher values than the real value. Another reason is the buffer capacity of the tea infusions. The buffer capacity of tea infusions has been studied by Tsuji \& Takeo (1983), and it is reported to be relatively low at the $\mathrm{pH}$ of our system $(\mathrm{pH} 5.5)$. However, a considerable buffer capacity still remains in the tea infusions. Tea infusions which contain more soluble material might tend to show lower values than the real values because of their higher buffer capacity.

In this system, samples could be injected every $3 \mathrm{~min}$, while it takes more than 20 min to measure individual catechins by HPLC (Komatsu et al., 1993; Goto et al., 1996). Although we have already developed a method to measure tea catechins using a biosensor, the time duration for the analysis was more than $5 \mathrm{~min}$ and the selectivity for EGCG was low (Horie et al., 1994). This new system is quite suitable for the rapid analysis of EGCG in green tea infusions and would be useful to estimate the taste or quality of green tea in combination with the amino acid biosensor which we have developed previously (Horie et al., 1993a,b). Using the FIA and the biosensor, it is possible to test tea infusions simultaneously with organoleptic and chemical methods.

EGCG is also a component of black tea, but the present method is not considered suitable for determining the EGCG content in black tea. In black tea, EGCG does not always have the major polyphenols while it does contain a considerable amount of ECG and theaflavin gallates (Ding et al., 1992), from which gallic acid may be produced by tannase. However, our FIA method has the possibility of being a rapid method for the estimation of the astringency of black tea because high correlations have been reported between astringency and the content of EGCG, ECG and theaflavin gallates in black tea (Ding et al., 1992; Owuor \& Obanda, 1995).

Acknowledgments The authors thank Dr. D. Coon, University of Hawaii, for assistance with the manuscript.

\section{References}

Chen, R.L.C. and Matsumoto, K. (1995). Enzymatic determination of gallotannin in green-tea infusions by a photometric flow-injection analytical method. Anal. Sci., 11, 777-780.

Ding, Z., Kuhr, S. and Engelhardt, U.H. (1992). Influence of catechins and theaflavins on the astringent taste of black tea blews. $Z$. Lebensm. Unters. Forsch., 195, 108-111.

Goto, T., Horie, H. and Mukai, T. (1993). Analysis of major amino acids in green tea by high-performance liquid chromatography coupled with OPA precolumn derivatization. Tea Res. J., 77, 29-33 (in Japanese).

Goto, T., Yoshida, Y., Kiso, M. and Nagashima, H. (1996). The simultaneous analysis of individual catechins and caffeine in green tea. J. Chromatogr. A, 749, 295-299.

Hara, Y. (1995). Prophylactic function of tea polyphenols. In "Food Phytochemicals for Cancer Prevention II," ed. by C.-H. Ho, T. Osawa, M.-T. Huang and R.T. Rosen, ACS, Washington DC, pp. 34-50.

Horie, H., Fukatsu, S., Mukai, T., Goto, T., Kawanaka, M. and Shimohara, T. (1993a). Quality evaluation on green tea. Sensors and Actuators B, 13-14, 451-454.

Horie, H., Mukai, T., Goto, T., Gonda, M. and Kawanaka, M. (1993b). An experiment on flow injection analysis of amino acids in tea infusion with enzyme sensors. Tea Res. J., 78, 53-60 (in Japanese)

Horie, H., Mukai, T., Goto, T., Kawanaka, M. and Shimohara, T. (1994). Measurement of tea catechins using biosensors. J. Jpn. Soc. Food Sci. Technol., 41, 433-435.

Ikegaya, K., Takayanagi, H. and Anan, T. (1990). Quantitative analysis of tea constituents. Tea Res. J., 71, 43-74 (in Japanese).

Komatsu, Y., Suematsu, S., Hisanobu, Y., Saigo, H., Matsuda, R. and Hara, K. (1993). Effects of $\mathrm{pH}$ and temperature on reaction kinetics of catechins in green tea infusion. Biosci. Biotech. Biochem., 57, 907 910.

Murachi, T. and Tabata, M. (1988). Use of immobilized enzyme column reactors in clinical analysis. Methods Enzymol., 137, 260271.

Nakagawa, M. (1972). The relationship between astringency and the reaction aspects of astringents for protein. Nippon Shokuhin Kogyo Gakkaishi, 19, 531-537 (in Japanese).

Nakagawa, M. (1975). Chemical components and taste of green tea. $J A R Q, 9,156-160$.

Nakagawa, M. and Nakajima, H. (1972). Chemical make-up of green tea liquor. Tea Res. J., 37, 79-83 (in Japanese).

Owuor, P.O. and Obanda, M. (1995). Changes of astringency by black tea due to the variations in individual theaflavins. Proceedings of ' 95 International Tea-Quality-Human Health Symposium, pp. 201 205.

Schügerl, K., Hitzmann, B., Jurgens, H., Kullick, T., Ulber, R. and Weigal, B. (1996). Challenges in integrating biosensors and FIA for on-line monitoring and control. TIBTECH, 14, 21-31.

Schwedt, G. and Stein, K. (1994). Immobilized enzyme as tools in food analysis. Z. Lebensm. Unters. Forsch., 199, 171-182.

Takayanagi, H., Anan, T., Ikegaya, K. and Nakagawa, M. (1985). Variation of chemical constituents during the development of tea shoots. Tea Res. J., 61, 20-25 (in Japanese).

Tsuji, K. and Takeo, T. (1983). Buffer capacity curves of green tea. Nippon Nôgeikagaku Kaishi, 57, 461-463 (in Japanese).

Ukeda, H. (1995). Food analysis biosensor-flow injection analysis methods. Nippon Shokuhin Kagaku Kogaku Kaishi, 42, 849-858 (in Japanese).

Yamamoto, M.M. (1996). Physiological modulative functions of tea. Nippon Shokuhin Kagaku Kogaku Kaishi, 43, 653-662 (in Japanese). 